\title{
AN MCDM APPROACH FOR CROP PATTERN SELECTION
}

\begin{abstract}
Crop pattern selection is a major agricultural decision problem. As it affects the society as well as the economic and environmental conditions, to prevent failures and imbalance, a scientific approach should be utilized instead of utilizing intuitive or experimental ones which are commonly used by some farmers. Accordingly, selection of the right crops necessitates the usage of a set of evaluation criteria. This study proposes a multiple criteria decision making approach based on the AHP method to aid farmers in their stone fruit pattern selection problem. To develop the decision hierarchy, a literature survey was conducted and opinions of the experts were collected. As a case study, the owner of an agricultural company planting stone fruits in southern region of Turkey participated in our study as a decision maker and replied pairwise comparison questions. As a result, the priorities of the alternatives plum, peach, apricot, and nectarine as well as the corresponding criteria to evaluate those stone fruits were revealed. The proposed model may be used for other farmers producing the same product in that region. The approach is flexible, by updating the decision hierarchy due to characteristics of different regions or crop patterns, it may be used at other crop pattern selection problems.
\end{abstract}

Keywords: agriculture, crop pattern selection, stone fruits, AHP.

\section{Introduction}

Selecting the right crops for cropping pattern optimization is an important decision problem for farmers as it has a great impact on social, economic, and environmental aspects.

Actually, some farmers are eager to select "what to plant" based on their experiences, trial and error methods, or word of mouth causing failures and imbalance in the cropping pattern of their region. This selection problem is affected by several factors such as land suitability, scarce resources, agricultural techniques, consumer preferences, financial status., etc. Therefore, the selection problem on hand necessitates a multi criteria decision making (MCDM) approach.

The fundamental motivation of this study is to prevent farmers to face unsuccessfulness due to wrong crop selection. For that reason, this study aims to aid farmers in their crop pattern selection decision by utilizing an AHP based MCDM approach.

\section{Literature Review}

To make farm-level decisions, researchers used mathematical programming approaches. Due to the development of agricultural technologies and the diversity in farming, the complexity of farm-level decisions has increased and MCDM approaches were used for agricultural planning (Hayashi, 2000; Montazar and Gaffari, 2012).

Particularly, the AHP method has been applied on various agricultural decision problems. For instance, in a recent study, Neissi et al. (2020) analyzed pressurized irrigation systems in Izeh plain, Iran and utilized the AHP method for selecting a suitable one. There are also 
ISAHP Article: A Style Guide for Paper Proposals To Be Submitted to the International Symposium on the Analytic Hierarchy Process 2020, Web Conference.

many researches about crop planning utilizing the AHP method. Cobuloglu and Buyuktahtakın (2015) utilized stochastic AHP to evaluate biomass crops for biofuel production in Kansas. Montazar and Gaffari (2012) developed an AHP model for selecting an optimized cropping pattern in northern part of Iran. The alternative set consists of barley, wheat, corn, vegetables, alfalfa, cotton, and summer crops. Huang and Zhang (2020) proposed an integrated decision approach utilizing AHP and fuzzy TOPSIS for selecting the optimal economic crop in minority regions of the Renai and Xinyi Township of Taiwan. To the best of our knowledge, our study would be the first one utilized for stone fruit crops evaluation and probably the first case study in Turkey.

\section{Hypotheses/Objectives}

This study aims to propose a decision model utilizing an AHP based MCDM approach for the farmers who want to select an appropriate stone fruit to plant. As a case study, stone fruit selection of an agricultural company in southern region of Turkey was taken into consideration.

\section{Research Design/Methodology}

There are three main stages at treating problems in an MCDM environment.

We structured a decision model in the first stage. We conducted an intensive literature survey using the keywords "crop pattern", "crop planning", "crop selection", "fruit selection", "AHP", "ANP", and "decision making". The survey results yielded a preliminary list of evaluation factors that can be used in the selection problem. Then, we held a meeting with five experts who are the executives of the agricultural companies planting stone fruits in southern region of Turkey. They discussed and finalized the list of factors due to the characteristics of their region and the stone fruits were considered as alternatives, namely plum, peach, apricot, and nectarine.

At the second stage, modeling, we developed a decision hierarchy. After having the experts determine the possible relations among the constituents of the problem, we realized that an AHP model would be more appropriate as we confronted lack of relations. Then, the experts arranged the factors in the final list into groups to form a decision hierarchy. Thus we came up with criteria (groups) and sub-criteria (evaluation factors). At the last step of the modelling stage, we aimed to pose pairwise comparison questions to experts to reveal the priorities of the criteria and the sub-criteria and then to have experts rate the alternatives through AHP rating approach. Unfortunately, because of the COVID-19 pandemic, we could not have held a new meeting where the experts would discuss and reply these questions. Only one owner of an agricultural company participated in this step as a volunteer.

At the last stage, analysis, we used super decisions software to compute the priorities of the criteria, the sub-criteria, and the alternatives.

\section{Data/Model Analysis}

The decision hierarchy developed is given in Figure 1. As can be seen, there are 7 criteria, 15 sub-criteria, and 4 alternatives at the hierarchy.

An excerpt from the pairwise comparison questionnaire is given in Appendix.

The priorities of the constituencies of the decision hierarchy are given in Table 1 and 2 . We also checked the inconsistencies and realized that they were under $10 \%$. 
ISAHP Article: A Style Guide for Paper Proposals To Be Submitted to the International Symposium on the Analytic Hierarchy Process 2020, Web Conference.

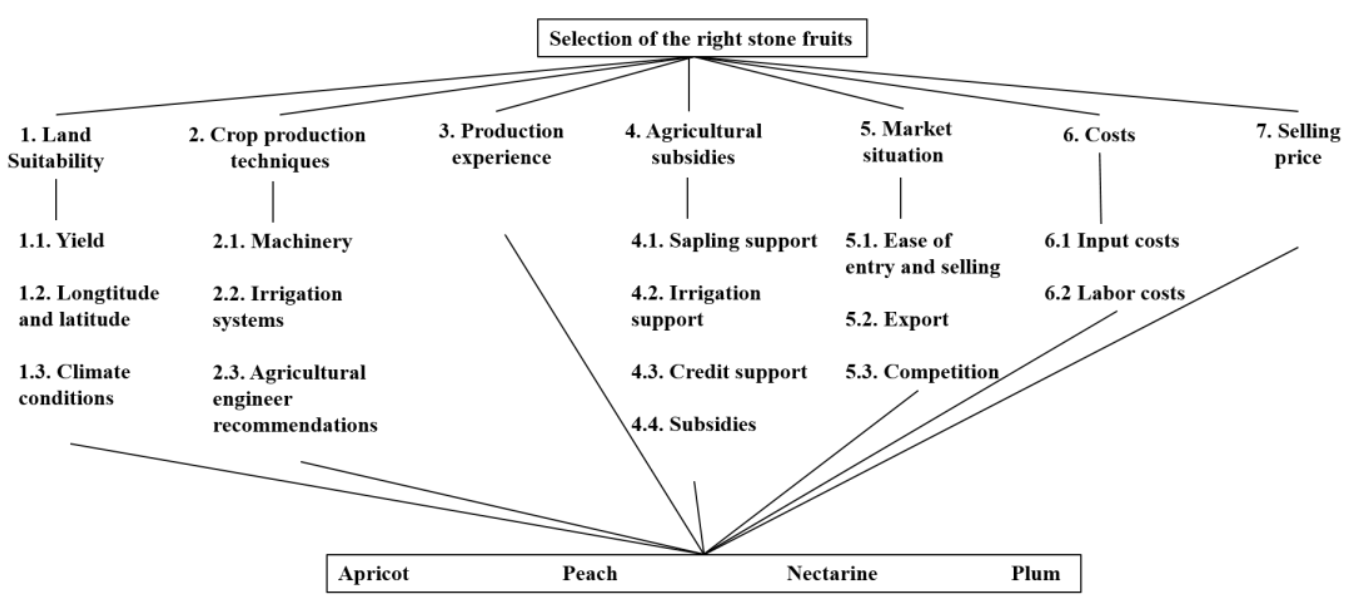

Figure 1. The AHP Model

Table 1. The unweighted super matrix representing importance of criteria and sub-criteria

\begin{tabular}{|c|c|c|c|c|c|c|c|}
\hline & & Goal & $\mathrm{C} 1$ & $\mathrm{C} 5$ & $\mathrm{C} 2$ & $\mathrm{C} 4$ & C6 \\
\hline \multirow[t]{7}{*}{ Criteria } & 1. Land suitability & $50.2 \%$ & & & & & \\
\hline & 5. Market situation & $19.2 \%$ & & & & & \\
\hline & 7. Selling price & $16.3 \%$ & & & & & \\
\hline & 3. Experience & $6.5 \%$ & & & & & \\
\hline & 4. Subsidies & $3.8 \%$ & & & & & \\
\hline & 2. Production techniques & $2.6 \%$ & & & & & \\
\hline & 6. Costs & $1.6 \%$ & & & & & \\
\hline \multirow[t]{15}{*}{ Subcriteria } & 1.1. Yield & & $47.37 \%$ & & & & \\
\hline & 1.3. Climate & & $47.37 \%$ & & & & \\
\hline & 1.2. Longititude \& latitude & & $5.26 \%$ & & & & \\
\hline & 5.1. Marketing & & & $77.85 \%$ & & & \\
\hline & 5.2. Export & & & $17.99 \%$ & & & \\
\hline & 5.3. Competition & & & $4.16 \%$ & & & \\
\hline & 4.1. Sapling support & & & & & $31.25 \%$ & \\
\hline & 4.2. Irrigation support & & & & & $31.25 \%$ & \\
\hline & 4.3. Credit support & & & & & $31.25 \%$ & \\
\hline & 4.4. Subsidies & & & & & $6.25 \%$ & \\
\hline & 2.2. Irrigation systems & & & & $78.70 \%$ & & \\
\hline & 2.3. Engineer recommen. & & & & $16.73 \%$ & & \\
\hline & 2.1. Machinery & & & & $4.57 \%$ & & \\
\hline & 6.2. Labor costs & & & & & & $83.33 \%$ \\
\hline & 6.1. Input costs & & & & & & $16.67 \%$ \\
\hline
\end{tabular}

\section{Limitations}

The main limitation of this study is the number of experts participated in the pairwise comparison and rating steps. Sensitivity analysis should be conducted. 
ISAHP Article: A Style Guide for Paper Proposals To Be Submitted to the International Symposium on the Analytic Hierarchy Process 2020, Web Conference.

Table 2. The rating scores of stone fruits

\begin{tabular}{|c|c|c|c|c|c|}
\hline & $w$ & Peach & Nectarine & Plum & Apricot \\
\hline 1.1. Yield & $23.77 \%$ & 5 & 4 & 2 & 1 \\
\hline 1.3. Climate & $23.77 \%$ & 5 & 4 & 2 & 1 \\
\hline 7. Selling price & $16.26 \%$ & 5 & 4 & 2 & 1 \\
\hline 5.1. Marketing & $14.91 \%$ & 3 & 3 & 3 & 3 \\
\hline 3. Experience & $6.46 \%$ & 3 & 3 & 3 & 3 \\
\hline 5.2. Export & $3.45 \%$ & 5 & 2 & 1 & 1 \\
\hline 1.2. Longititude \& latitude & $2.64 \%$ & 3 & 3 & 3 & 1 \\
\hline 2.2. Irrigation systems & $2.03 \%$ & 3 & 3 & 3 & 3 \\
\hline 6.2. Labor costs & $1.34 \%$ & 3 & 3 & 3 & 3 \\
\hline 4.1. Sapling support & $1.17 \%$ & 3 & 3 & 3 & 3 \\
\hline 4.2. Irrigation support & $1.17 \%$ & 3 & 3 & 3 & 3 \\
\hline 4.3. Credit support & $1.17 \%$ & 4 & 4 & 2 & 2 \\
\hline 5.3. Competition & $0.80 \%$ & 5 & 4 & 2 & 1 \\
\hline 2.3. Engineer recommen. & $0.43 \%$ & 4 & 2 & 2 & 2 \\
\hline 6.1. Input costs & $0.27 \%$ & 3 & 3 & 3 & 3 \\
\hline 4.4. Subsidies & $0.23 \%$ & 3 & 3 & 3 & 4 \\
\hline 2.1. Machinery & $0.12 \%$ & 4 & 3 & 3 & 2 \\
\hline \multicolumn{2}{|c|}{ Rating scores } & 4.40 & 3.67 & 2.30 & 1.47 \\
\hline
\end{tabular}

\section{Conclusions}

The participant company was recommended to plant peach when yield, climate, and selling price were the most important factors. The proposed approach will be utilized in other agricultural companies planting stone fruits in southern region of Turkey and then a sensitivity analysis may be conducted. In this case, the aggregated conclusions will be fruitful for all of the stone fruit farmers in the region. The authors are planning to contact with companies planting citrus in the same region as the model can be utilized for other crop patterns and also in other regions after being revised accordingly.

\section{Key References}

Cobuloglu, H. I. \& Büyüktahtakın, İ. E. (2015). A stochastic multi-criteria decision analysis for sustainable biomass crop selection. Expert Systems with Applications, 42(15), 6065-6074

Hayashi K. 2000. Multi-criteria analysis for agricultural resource management: a critical survey and future perspectives. European Journal of Operational Research, 122, 486-500

Huang, W. \& Zhang, Q. (2020). Selecting the optimal economic crop in minority regions with the criteria about soil and water conservation. Agricultural Water Management, 241, 106295

Montazar, A. \& Gaffari, A. (2012). An AHP model for crop planning within irrigation command areas. Irrigation and Drainage, 61(2), 168-177.

Neissi, L., Albaji, M., \& Boroomand Nasab, S. (2020). Combination of GIS and AHP for site selection of pressurized irrigation systems in the Izeh plain, Iran. Agricultural Water Management, 231, 106004. 
ISAHP Article: A Style Guide for Paper Proposals To Be Submitted to the International Symposium on the Analytic Hierarchy Process 2020, Web Conference.

\section{Appendix}

Which of the following factors has a greater influence on "the selection of stone fruit to plant"?

1=Equal $3=$ Moderately more $5=$ Strongy more $7=$ Very strongly more $9=$ Extremely more

\begin{tabular}{|l|l|l|l|l|l|l|l|l|l|l|l|l|l|l|}
\hline $\begin{array}{l}\text { Land suitability for crop } \\
\text { production }\end{array}$ & 9 & 8 & 7 & 6 & 5 & 4 & 3 & 2 & 1 & 2 & 3 & 4 & 5 & 6 \\
\hline $\begin{array}{l}\text { Technical issues about the } \\
\text { crop production }\end{array}$
\end{tabular}

